\title{
L5 Vertebra
}

National Cancer Institute

\section{Source}

National Cancer Institute. L5 Vertebra. NCI Thesaurus. Code C32903.

The fifth lumbar vertebra counting from the top down. 